\section{EMBRYRIDDLE}

Aeronautical University

SCHOLARLY COMMONS
Journal of Aviation/Aerospace

Education \& Research

Volume 2

Number 3 JAAER Spring 1992

Article 7

Spring 1992

\title{
Producing a Workshop for Training Airline Instructors
}

Ross Telfer

John Bent

Follow this and additional works at: https://commons.erau.edu/jaaer

\section{Scholarly Commons Citation}

Telfer, R., \& Bent, J. (1992). Producing a Workshop for Training Airline Instructors. Journal of Aviation/ Aerospace Education \& Research, 2(3). https://doi.org/10.15394/jaaer.1992.1077

This Article is brought to you for free and open access by the Journals at Scholarly Commons. It has been accepted for inclusion in Journal of Aviation/Aerospace Education \& Research by an authorized administrator of Scholarly Commons. For more information, please contact commons@erau.edu. 


\title{
PRODUCING A WORKSHOP FOR TRAINING AIRLINE INSTRUCTORS
}

\author{
Ross Telfer, Ph.D. and John Bent
}

\begin{abstract}
An innovative workshop was designed to train line instructors for Cathay Pacific Airways. The program constraints were demanding: minimum time off-line for participants; maximum credibility in terms of perceived relevance; and capability of operation in-house. The design and trial of the workshop are described in this paper, with details of the content, presentation, materials, and evaluation.
\end{abstract}

\section{INTRODUCTION}

Airline line instructors are usually training captains. In the past, preparation for this role relied on an appropriate depth of experience and suitable personal characteristics. A training captain was judged by the company to be adequate for the task in terms of operational skills, an exemplary professional record and experience. There was little consideration of aptitude for, or ability in, instruction. A change in this perception was forced by the unpredictability of demand for airline trainers. In the past, airlines have ridden the wave of growth. While the boom-bust cycle is clearly identifiable, the precise phase of the cycle is usually identified only in retrospect and has become increasingly difficult to foresee. Periods of growth and staff training needs have often occurred with insufficient notice to permit planning and implementation of systematic training programs.

Because a major problem has been the cost of taking pilots from the line for extensive training, line training has been dominated by short-term needs and virtual crisis management. The rapid growth, the costs, and the need for special training equipment combine with severe time constraints to provide a formidable challenge for the instructional designer, as well as for the training advocate who needs to convince company accountants.

Probably the most telling argument against change in the methods of preparing line instructors is that airlines have been meeting the challenge successfully to date. At least, there is little evidence to suggest that airlines have not been able to meet the training challenge. The subtlety of this argument lies in the fact that results of effective training are difficult to quantify in the short term. Effects are pervasive and imprecise, rather than instantaneous and unambiguous: in other words, qualitative rather than quantitative. In the longer term it may be possible to demonstrate a significant correlation between training and safety. While apparent, such a link is difficult to prove because of the relatively low frequency of accidents.

The main reason the traditional method of line instructor preparation has worked to date is because the pilots selected to do line training are progressively exposed to a variety of flight conditions and demands which must be resolved instant- ly. This on-the-job training and depth of experience is brought with them to the training class.

The motivation and perseverance of aircraft pilots (which is a sought after occupation), and their cooperative norm, have sustained line instruction in the past. Given the expertise and experience of pilots, few instructor training systems would not have worked. Pilots are a motivated and reasonably expert group. They are able to take the initiative to do what is necessary to meet the training demands placed on them.

There is evidence, however, that things are changing (Telfer \& Moore, 1989). Crisis management and cycles of rapid growth can compromise selection and promotion criteria. Airlines can no longer assume that all pilots will be from the upper end of the experience continuum.

REASONS FOR CHANGE

Why change the system? The reasons for change are found in feedback from trainees critical of the line instruction they received. The major weakness cited is the lack of suitable line instruction for the trainee, especially the relatively inexperienced trainee, in the allimportant first contact with the company. Mediocre or uninspir- 
ed line training naturally reduces the individual's interest, motivation, and commitment. If the effectiveness of line training is questionable, ultimately it is probable that there will be substantiation in longitudinal safety statistics, failure rates, need for additional training, and off-line time because of the slower assumption of productive duties. It is argued that cost effectiveness will demonstrably suffer when the evidence is accumulated over time.

Another cause of change in training methods is the operation of regional airline services on a code-sharing basis with major carriers. Integration of pilot training offers the advantage of improving regional airline safety. (Daly, 1991).

Using one airline as an example, the immediate impetus for change came from four sources:

1. Trainee evaluation provided feedback of training limitations in meeting individual needs. Clarity of explanation, encouragement or motivation, and instructional methods in general were mentioned.

2. The potential link between aircraft accidents, human factors, and training procedures was persuasive.

3. Cockpit Resource Management (CRM) (Aircrew Team Management) programs are demonstrating positive results. A similar development in line instructor preparation is an obvious, if unprecedented, parallel.

4. A period of rapid growth and recruitment emphasised the importance of a systematic supply of aircrew with an assured level of competence. Cadet entry schemes can be compelling, too.

The new workshop was intended to address trainee, line instructor, and company perceptions of dissatisfaction with contemporary instructor training. High recruitment levels meant unprecedented demand on the preparation of line instructors, so the design had to incorporate a training-oftrainers or multiplier principle. Apart from this quantitative factor, there was a qualitative element. Specifically, the instructional design was centered on the trainee, rather than on the instructor. Objectives and evaluation were based on what the trainee was to demonstrate as a result of instruction.

The workshop sought to reinforce the participatory and process oriented model which a CRM program had introduced to the company two years previously. Statistical evidence of the value of such an approach is not yet available, but the high face validity was considered sufficient justification for an extension and consolidation of the design. For example, the use of in-house videotapes of training sessions had clear benefits in identification and acceptance. These benefits were considered to outweigh the professionalism of commer- cially produced videotapes.

\section{OBJECTIVES}

The workshop was designed to improve both the effectiveness and the efficiency of line instruction, within the dual constraints of time and expense. In particular, it sought to introduce training captains to instructional theory and practice, enabling them to exploit their personal strengths of personality and experience. This is a marked difference in aim from the CRM program, but they retain a common approach through inhouse development, process orientation, and participatory method.

Of the 176 members of the Check and Training Department, the workshop's focus was initially on new training captains, with experienced captains participating afterwards. The intention was to provide specific knowledge, values, and methods which would enhance the potential for instruction. The broad objective was to make instruction traineecentred, helping the individual to meet company needs.

In specific terms, at the end of the workshop participants are expected to be able to meet the following objectives.

Identify non-verbal communication Inconsistent with verbal communication

Videotaped examples are provided of posture, gesture, and expression incompatible with an instructor's attempt to be sincere and helpful.

Specify Instructional intentions as trainee-oriented behavioural objectlves 
There is a tendency for instructors to express objectives in terms of what they propose to accomplish. A valuable tool for both instruction and assessment is to make objectives trainee-centered by stating what the trainee has to demonstrate as having been learned.

Devise and Implement an evaluation consistent with objectlves

If objectives are expressed in an appropriate level of trainee performance, criteria for success are clear for both trainee and instructor.

Recognise and compensate for the effects of stress on trainees

In keeping with the traineecentered approach, instructor empathy is regarded as a key attribute. Sources of trainee stress and anxiety, and possible solutions, are a focus for instructor discussion.

Recognise and adlust the trainee level of arousal

The consequences in the learning process for overconfidence and exuberance can be contrasted with the effects of under-achievement and lack of confidence.

Apply methods which will facillate Information processing

Given an understanding of the ways in which the sensory register, and short-term and long-term memory operate, instructors can provide trainees with keys or codes to help them to process and retain information.

Apply a three-stage model of skill acquisition
Skill acquisition is analysed so that three stages are recognisable: First, there is a cognitive level at which the trainee becomes familiar with what has to be done.

Next comes the demonstration and practice so that sequences and movements become fixed.

Finally, there is the autonomous level at which the skill is automatic.

Use the instructional skills of reinforcement, variabillty and questioning

From the range of specific skills isolated by researchers Waxman \& Walberg, 1991), emphasis was placed on motivating trainees, varying the instructional approach, and using questions effectively. This selection was based primarily on perceived relevance for aviation instruction and on the knowledge that refresher courses could extend the coverage to other skills such as explaining, beginning and ending instruction, individualising instruction, and so on.

Recognise the Importance of trainee activity las opposed to passivity) as a medlum for learning

Contemporary instructional psychology (Telfer \& Biggs, 1987) recognises the importance of the trainee's active involvement in the process of learning. This helps instructors to consider ways in which trainees can be involved further. Unk Instructional art and craft

Given that many of the participants were, knew, or had learned from first-rate natural instructors, the workshop was based on the rationale that they should also be aware that there is a growing body of testable theory to guide instructors (Waxman \& Walberg, 1991). Instructors were encouraged to combine their personal art of instruction with the craft of instruction introduced in the workshop and in the associated reading material.

\section{INSTRUCTIONAL DESIGN}

The most restrictive factor on the design of a line instructor training program was the need for minimal impact on the airline's day-to-day operations. Line instructors are senior pilots needed for operations, and few can be spared at any one time. This means that the workshop can have a small number of pilots for only the time needed to effect higher standards of effectiveness in instruction.

The relative brevity of the work-shop duration dictated the following six design features for the Line Instructor Training Workshops:

First, the workshops would be organised and staffed in-house, so the training was based on the multiplier principle. In other words, line instructors would be trained as trainers who could conduct work-shops in line instruction. The materials and manuals of instruction would eventually be modular so that actual workshops could be varied to suit participants' prior experience, even to the extent of having attended a previous workshop.

Second, given the maturity of the learners, the workshop was 
designed on the basis of androgogy (adult psychology) rather than pedagogy (child psychology) (Jarvis, 1987). The ways adults learn are distinctive, especially in terms of selfdirection, individual differences, and extent of experience. Research on instructional effectiveness is incorporated both as content and as a conceptual foundation. For example, positive reinforcement, enthusiasm, empathy, and clarity are emphases in the way the course is presented. This approach relates to the next design feature.

Third, the process of preparing line instructors would be given equal priority with content so that doing, rather than telling, was preeminent. In simple terms, the "how" and "why" were given the same weight as the "what". Peer presentations, and peer production of videotapes, are key aspects of the workshop. Participants see that it is their colleagues, not outside specialists, who are demonstrating the skills and values, and presenting the knowledge. This has the advantages of both credibility and motivation.

Additionally, the medium would further support the process and content. Thus the workshop and the materials demonstrated the skill of variability they advocated. Learning activities and the nature of the participants' involvement were deliberately scheduled and varied to suit the complexity of the task and the time of the day. Visual aids were simple but reinforcing or exemplary. For example, coloured magnetic cards, charts, and short special-purpose videotapes were integrated.

The process gains importance, too, from the fact that each workshop consists of participants from different fleets and varying experience. The intention is to facilitate the flow of ideas from fleet to fleet, and up and down the seniority level.

Fourth, because of the need to make maximum use of the participants' time before and after the actual workshop, the educational process was extended beyond the twenty-five hours of timetabled instruction. Presage (Biggs \& Telfer, 1987) was covered by the distribution of pre-reading two weeks or so prior to the workshop. A manual was provided for later reference and a presenter's guide detailed the actual process of presenting such a workshop in the form of a script with blanks for instructors to complete as they wished. By means of these written sources the course is standardised in concept and design, yet open to individual presentation. There is a takeaway, pocket-size, course summary card using the mnemonic KEEP IT (Knowledge, Enthusiasm, Empathy, Praise, Instructional Technique). Together with the manual, it provides a permanent reminder of the training principles.

Throughout, individual differences are recognised with instructors encouraged to base instructional styles on their personal strengths drawn from both experience and personality. Anecdotal examples, especially of the humorous type, were given a place in the design. The essence is one of extending options and alternatives, not in prescribing any one approach (Telfer \& Biggs, 1988). While the importance of 'chunks' in information processing is a key concept in the instructional methods introduced in the workshop, the examples used by each instructor (or facilitator) differ. The presenter's guide standardised the essential course methods and content.

In the trial workshop the idea of developing an instructor's repertoire was extended in the form of a metaphoric tool box. As the workshop proceeded, the box was gradually filled with a variety of special tools which could then be selected and used when the instructor needed them.

Fifth, as a conceptual map (Posner \& Rudnitsky, 1986) a spiral curriculum design was used. On the first day, essential knowledge, skills and values are introduced, and are reinforced on the second and third days with increasing depth. This idea follows the notion of an "ordered tree": a graphic pattern formed by the linkages in the basic course components (Reitman \& Reuter, 1980). Each day a more demanding practical session is provided.

Finally, practicality and credibility for the practitioner are key criteria. The workshop has to provide a demonstrably better way of handling line instruction, 
and it has to be capable of implementation by the professional pilot with limited preparation time. The presenter group will grow as the number of workshops increase, spreading the ideas throughout the airline training system on a multiplier principle.

An initial workshop with four senior line captains was run to debug both the content and the process. The group was hypercritical of jargon, of psychobabble, of unrelated theory, of verbosity, and of circumlocution. The procedure for this workshop was to present a segment, discuss it critically, then edit the presenters' guide or change the manual.

\section{COURSE COVERAGE}

The content of training for line instructors was drafted by a senior Check Captain and by an educationalist in a series of planning sessions. An initial basis came from consultant programming in the form of the existing training workshop (which had been operating for four years) and evaluations of it made by participants. The draft was then refined by a team of six senior training Captains (two from each of the fleets operated by the company).

On Day 1 the major topics are instructional effectiveness; verbal and non-verbal communication; the specifics of line training; objectives and evaluation; and instructional styles.

The topics on the second day are briefing and debriefing; stress and arousal; instructional methods;information processing; how a skill is learned; fault analysis and remediation.

The final day includes microskills; judgement and airmanship; command training; the cadet entry scheme; use of simulator video equipment; and workshop evaluation.

Course Pre-reading consists of a 24 page booklet which includes the workshop timetable and an introduction to and rationale for the course. Responses prepared by participants help to provide a mental set for the workshop sessions, and information the presenter can use for preparation and for input to discussion. Throughout such discussions participants have an informal opportunity to compare their views with their peers' views, and to expand their range of instructional options.

* Each participant prepares three short lessons from lists of suggestions. The three lessons are grouped into knowledge, skill, and attitude/ airmanship categories.

* Preparation in this presage stage also includes responding to questions on participants' concems about the workshop, their expectations, and their description of the role of a line instructor.

* Participants are asked to consider and record a personal insight into learning effectiveness, especially as it relates to helpful explanation.

* From a list provided, participants select the qualities which they regard as most important for line instructors.

* Example scenarios are provided for the debriefing exercise.

* A standardised personal type indicator is included. This is handed in on arrival at the workshop, scored privately, then returned to the participant on the last day of the workshop. Results are confidential and are designed for selfawareness.

The Presenter's Guide is a 39 page booklet providing the format of the workshop and the principles underlying its design. These principles include identifiable domains of learning; trainee-centred instruction; the spiral curriculum; emphasis on the visual medium; flexibility in the details and examples; credibility of presenters; and active rather than passive learning.

Scenarios for use in the final, unprepared practical session are included. For example, one scenario reads: 'Your new F/O (ex fast jet military) is overcontrolling the aircraft on departure and approach. The first rotation was too fast. Debrief."

The Guide is presented session by session with two columns per page, one for "Visual Aids and Cues" and the other providing "Script and Explanations." Included in the Guide are instructions for conducting the formative and summative evaluations.

As Appendices, the Guide includes backup sessions which can be incorporated if 
the pacing proves fast or the participant experience is such that the scheduled content is covered and time remains. Such Appendices are the genesis of the modular approach to be developed.

The 107 page Course Manual is designed for use both during and after the workshop. The manual goes beyond the content presented in the workshop to provide both depth and a stimulus for reflection. The manual also follows the structure of the workshop (Day 1, Session 1, etc.,) but the information is presented in textbook format. For example, on Day 1, Session 2, for which the topic on the timetable is "Instructional Effectiveness," the course manual provides a three page exposition of What We Know About Effective Instruction' (including a summary of research findings); a list a specific instructional characteristics which facilitate learning; the implications for the line instructor; and the practical applications in the preinstruction, instruction, and postinstruction phases. There are two review questions with space for responses.

\section{TIMETABLE}

The three day course begins each morning at 0830 and concludes at 1700 . After deliberation, it was decided not to utilize evening sessions as the workshop is not residential and the sessions run from 0830$1030,1045-1230,1330-1530$, and 1545-1700 hours. Interspersed are coffee breaks (in a lounge/kitchen area outside the workshop room) and a lunch break. The lunch is provided at an aviation club five minutes' drive from the workshop centre. A company bus provides transportion.

The first sessions begin with an introduction to the day's activities and a review of the previous day. Morning sessions are used for theoretical and conceptual issues. Videotapes and practical sessions are more common as the day progresses. A total of eleven training videotapes are used, most of which are written and produced in-house and star Cathay air crew personnel. The placement corresponds with sections in which lighter material or relief from a sustained activity is needed.

There are four practical sessions in which participants practice instruction in a simulated cockpit of a desk and two chairs. The practical sessions focus on teaching knowledge, skill, attitudes or airmanship, and on debriefing techniques.

$$
\text { EVALUATION }
$$

Evaluation is conducted at both formative and summative levels with time scheduled to ensure they both occur (May et al, 1987).

After six months, thirty participants provided oral formative and written summative evaluations of the workshop. Themost common formative criticism related to adherence to structure in the workshop. Some participants sought minor changes in the timetable, variation in coffee breaks, or continuation of a discussion.
The summative evaluation provided the responses shown in Table 1.

As a generalised interpretation, negative comments (such as 'premature termination of interesting topics") tended to come from the more experienced participants. New trainers were more positive. Nevertheless, the figure of $69 \%$ "satisfied" with the Workshop Content (Table 1) implies some concern for relevance.

In their commentaries respondents regarded the workshop as "useful///interesting'/"excellent" (77\%). The most frequent criticism was of too many "buzz words"/"definitions" or an "academic approach' (30\%) which was regarded by some as distracting. Approximately $20 \%$ of the respondents commented on the need to improve the professionalism of the videotapes and provide more practicals and debriefings. They praised the command training component.

A smaller proportion (15\%) believed more constructive criticism was needed in the practical sessions, questioned the need for the Myers-Brigg Indicator, wanted the professional segment more relevant to aviation, and sought a greater orientation for flight engineers. The participants also thought the use of two presenters rather than one was important.

As a result of the initial evaluation, the workshop has been refined to provide more practical sessions and guidance in fault analysis. Special effort will be made by present- 
Table $1(\mathrm{~N}=30)$

Participant Evaluation

\begin{tabular}{|c|c|c|c|c|}
\hline Workshop Content & $\begin{array}{c}\text { Very Satisfied } \\
25 \% \\
\end{array}$ & $\begin{array}{c}\text { Satisfied } \\
69 \% \\
\end{array}$ & $\begin{array}{c}\text { Dissatisfied } \\
6 \% \\
\end{array}$ & \\
\hline Workshop Materials & $\begin{array}{c}\text { Valuable } \\
10 \%\end{array}$ & $\begin{array}{l}\text { Useful } \\
48 \%\end{array}$ & $\begin{array}{c}\text { Of Some Use } \\
34 \%\end{array}$ & $\begin{array}{c}\text { Useless } \\
7 \%\end{array}$ \\
\hline Use in Future? & $\begin{array}{l}\text { Yes } \\
64 \%\end{array}$ & $\begin{array}{l}\text { No } \\
7 \%\end{array}$ & $\begin{array}{c}\text { Perhaps } \\
29 \%\end{array}$ & \\
\hline $\begin{array}{c}\text { Practical Activities } \\
\cdot\end{array}$ & $\begin{array}{c}\text { Valuable } \\
63 \%\end{array}$ & $\begin{array}{l}\text { Useful } \\
30 \%\end{array}$ & $\begin{array}{c}\text { Some Use } \\
3 \% \\
\end{array}$ & \\
\hline Video Taping Useful? & $\begin{array}{l}\text { Yes } \\
69 \% \\
\end{array}$ & $\begin{array}{l}\text { No } \\
14 \%\end{array}$ & $\begin{array}{c}\text { Sometimes } \\
17 \%\end{array}$ & \\
\hline Appropriate Presentation? & $\begin{array}{l}\text { Yes } \\
86 \% \\
\end{array}$ & $\begin{array}{l}\text { No } \\
3 \%\end{array}$ & $\begin{array}{c}\text { Sometimes } \\
10 \%\end{array}$ & \\
\hline Schedule & $\begin{array}{l}\text { Appropriate } \\
86 \%\end{array}$ & $\begin{array}{l}\text { Inappropriate } \\
14 \%\end{array}$ & & \\
\hline Pace & $\begin{array}{l}\text { Appropriate } \\
90 \%\end{array}$ & $\begin{array}{c}\text { Inappropriate } \\
10 \%\end{array}$ & & \\
\hline Facilities & $\begin{array}{l}\text { Sultable } \\
76 \%\end{array}$ & $\begin{array}{l}\text { Unsuitable } \\
24 \%\end{array}$ & & \\
\hline
\end{tabular}

ers to utilize the expertise and background of experienced trainers. Illustrative material will be rewritten to simplify the language. A priority for the first session of each workshop will be to clarify theexpectations of participants. The manuals are being revised to clarify the purposes of the workshop (PreReading); to highlight the importance of demonstration (Manual); to indicate how to handle mistakes with honesty and humility (Manual); to provide general principles of report writing and apply instructional technique in the line situation (Manual). Further changes were considered but deferred until more workshops are conducted.

\section{THE NEXT STEP}

After the six initial workshops, two aspects have emerged as vital dynamics. First, participants have to be actively involved through interaction with the presenter and other participants. Second, the flexibility of the presenter to depart from the script has to be kept within clearly recognised limits. The essential content has to be protected from individual interpretation which can distort the intent and design. Lecturing is anathema to the rationale of the course, given the emphasis on the process and on the active involvement of trainees. The workshop is designed to model what it advocates.

To consolidate and revise knowledge and techniques, a one day refresher course has been proposed. This addition would complete the presage, process, and product stages of instruction. Line Instructors would then have available a cycle of professional preparation beginning with prereading, moving through workshop instruction, offering a reference manual on line experience, and providing a followup workshop. As line instructors complete this cycle of activities, the modular structure of the core workshop will enable a new cycle to begin with a change of content and method. This new approach to airline training is considered to have great promise. 
Ross Telfer, Ph.D., is Professor and Head of the Department of Aviation at the University of Newcastle, Australia. He is the coauthor of The Process of Learning and Psychology and Flight Training.

John Bent is a Senior Check Captain with Cathay Pacific Airways in Hong Kong, and is codesigner and manager of a new workshop for aircrew trainers. He has been flying for $\mathbf{3 0}$ years, both with the Royal Air Force and with three airlines in civil aviation. His training experience has included military flying instruction as a QFI, management of a small flying school in Germany, and development of a new multicultural preschool and primary school in Hong Kong.

\section{REFERENCES}

Biggs, J.B. and Telfer, R.A. (1987). The Process of Learning. Sydney: Prentice Hall.

Daly, K. (1991). Setting the Standard, Flight International, No. 4258, Vol 139, 13-19 March, pp 30-32. Janvis, P. (1987). Adult Learning in the Social Context. Beckenham, Croom Helm, 16-36.

May, LS., Moore, C.A. and Zammit, S.J. (1987). Evaluating Business and Industry Training. Boston: Kluwer, 1940.

Posner, G.J. and Rudnitsky, A.N.(1986). Course Design, New York: Longman, 25-35. Reitman, J.S. and Reuter, H.H. (1980). Organisation revealed by recall orders and confirmed by pauses. Cognitive Psychology, 12, 554-581.

Telfer, R. and Biggs, J.(1988). The Psychology of Flight Training. Ames, IA: lowa State University Press / Ames.

Telfer, R. and Moore, P.(1989). Pilot Learning Styles, Paper presented to the workshops on Flight Instruction for the 1990's. Australia: University of Newcastle.

Waxman, C.H. and Walberg, H.J. (1991). Effective Teaching: Current Research, Berkely, McCutchan Publishing Company. 